\title{
PELATIHAN DAN PEMBENTUKAN KADER PEDULI KB (KaPeKB) SEBAGAI UPAYA PENURUNAN KEMATIAN IBU DAN BAYI DI POSYANDU DUSUN BOPALA DESA MENGANTI KECAMATAN KESUGIHAN KABUPATEN CILACAP TAHUN 2017
}

\section{OLEH :}

\author{
Susanti $^{1}$, Engkartini ${ }^{2}$, Elisa Issusilaningtyas ${ }^{3}$
}

\section{A. DASAR PEMIKIRAN}

Angka Kematian Ibu (AKI) dan Angka Kematian Bayi (AKB) di Kabupaten Cilacap masih tinggi dan mendapatkan perhatian khusus dari Dinas Kesehatan Kabupaten. Dinas Kesehatan telah melakukan berbagai program untuk menekan AKI dan AKB. Angka kematian ibu di Indonesia sebesar 359 kematian per 100.000 kelahiran hidup pada tahun 2008-2012. Dibandingkan dengan target, rasio kematian ibu yang merupakan salah satu indikator Millenium Development Goals (MDG's) yang harus dicapai tahun 2015 yaitu 102 per 100.000 kelahiran hidup, maka AKI saat ini masih belum memenuhi target atau perlu diturunkan lagi (Kemenkes RI,2014a).

Beberapa faktor penyebab langsung Kematian ibu di Indonesia masih didominasi oleh perdarahan, eklampsia, dan infeksi. Sedangkan faktor tidak langsung penyebab kematian ibu karena faktor terlambat dan terlalu. Ini semua terkait dengan faktor akses, sosial budaya, pendidikan, dan ekonomi. Faktor risiko kematian ibu adalah terlalu tua hamil (hamil di atas usia 35 tahun) sebanyak. Terlalu muda untuk hamil (hamil di bawah usia 20 tahun), terlalu banyak (jumlah anak lebih dari 4) dan terlalu dekat (jarak antar kelahiran kurang dari 2 tahun). Hal ini diperkut oleh hasil penelitian bahwa ada pengaruh umur $(\mathrm{p}=0,002 ; \quad \mathrm{OR}=5,117), \quad$ jarak kehamilan $(\mathrm{p}=0,0001 ; \mathrm{OR}=16,512)$ (Deal Baby $\mathrm{E}$ dan Indawati $R, 2014$ )

Kementerian Kesehatan Republik
Indonesia telah meluncurkan "Program Perencanaan Persalinan dan Pencegahan Komplikasi (P4K) merupakan upaya terobosan dalam percepatan penurunan angka kematian ibu dan bayi baru lahir melalui kegiatan peningkatan akses dan kualitas pelayanan Kesehatan Ibu dan Anak (KIA) dan KB. Indikator keberhasilan $\mathrm{P} 4 \mathrm{~K}$ adalah persentase penggunaan metode $\mathrm{KB}$ pasca persalinan (Kemenkes RI, 2014b). Tujuan penggunaan KB diantaranya mewujudkan pendidikan dasar untuk semua, mendorong kesehatan gender dan pemberdayaan perempuan, memberantas kemiskinan dan kelaparan, menurunkan angka kematian anak, meningkatkan kesehatan ibu, memerangi penyebaran HIV/AIDS, malaria dan penyakit menular lainnya, memastikan kelestarian lingkungan hidup, membangun kemitraan global dalam pembangunan (Muryanta Andang, 2010).

Pertimbangan akseptor dalam menentukan pilihan jenis kontrasepsi salah satunya karena kurangnya pengetahuan tentang kesesuaian alat kontrasepsi dengan tujuan penggunaannya (kebutuhan), persyaratan dan keamanan metode kontrasepsi tersebut, tempat pelayanan dan kontraindikasi dan alat kontrasepsi yang bersangkutan. Pemahaman keluarga tentang kesehatan reproduksi termasuk pemilihan alat kontrasepsi dipengaruhi oleh pendidikan, pendapatan, pengetahuan tentang kesehatan reproduksi, akses informasi dan 
ketersediaan pelayanan kesehatan, serta tingkat pemahaman kesehatan reproduksi (Indrawati, 2011).

Berdasarkan hasil penelitian bahwa ada perbedaan pengetahuan antara kelompok diberi konseling dengan tidak diberi konseling dengan $\mathrm{p}<0,001$ ) dan ada perbedaan kemantapan dalam pemilihan alat kontrasepsi pada calon akseptor KB antara kelompok diberi konseling dengan tidak diberi konseling dengan $\mathrm{p}<0,001$ ). Hal ini disebabkan dengan konseling maka terjadi transfer informasi mengenai kelebihan, kekurangan, efektivitas dan efisiensi masing-masing alat kontrasepsi antara calon akseptor dengan petugas kesehatan. (Tumini, 2010).

Jumlah Pasangan Usia Subur (PUS) di Kabupaten Cilacap tahun 2012 sebesar 349.186 dengan peserta KB Baru sejumlah 244.256. dengan cakupan 69,95\%. Berdasarkan data BAPERMADES didapatkan data pada tahun 2013 di Kabupaten Cilacap sebesar 12,91\%.(BAPERMAS, 2013). Persentase akseptor KB aktif menurut jenis kontrasepsi terdiri dari IUD 9,9\%, MOP $0,2 \%$, MOW 2,3\%, Implan 18,1\%, kondom 5,0\%, suntik $41,5 \%$ dan pil 22,9\%. Jumlah peserta KB aktif sebanyak $68,8 \%$ atau 7.449 dari 10.825 PUS. Jumlah ini belum mencapai target standar pelayanan minimal $70 \%$ peserta KB aktif. (Profil Puskesmas Kesugihan II, 2015). Data pada bulan Juli 2016 terdapat 2 (dua) kejadian kematian ibu di wilayah Puskesmas Kesugihan II menambah jumlah kematian ibi di Kabupaten Cilacap dan masih banyak ditemukannya ibu hamil dengan risiko tinggi, dan masih banyak $4 \mathrm{~T}$ ( terlalu tua, terlalu muda, terlambat mengambil keputusan, terlambat dirujuk) (Profil Puskesmas Kesugihan II, 2015)

Program dan kebijakan yang dapat dilakukan oleh pemerintah untuk menurunan angka unmeetneed adalah memudahkan akses dan meningkatkan kualitas

pelayanan, menambah/mengembangkan jenis kontrsepsi, menekankan KIE, mendorong komunikasi antar pasangan dan memberikan jaminan $\mathrm{KB}$ gratis pada masyarakat miskin. Kader Peduli KB (KaPeKB) diharapkan juga mampu memberikan informasi tentang $\mathrm{KB}$, sehingga dapat menambah jumlah akseptor $\mathrm{KB}$.

\section{B. TUJUAN}

\section{Tujuan Umum:}

Untuk meningkatkan pengetahuan masyarakat tentang Keluarga Berencana

\section{Tujuan Khusus:}

1. Untuk meningkatkan pengetahuan masyarakat dan kader tentang Keluarga Berencana khsusunya alat kontrasepsi.

2. Terbentuknya Kader Peduli Keluarga Berencana (KaPeKB)

\section{BENTUK KEGIATAN}

Bentuk kegiatan pembentukan dan pelatihan Kader Peduli KB (KaPeKB) sebagai upaya peningkatan pengetahuan dan ketrampilan konseling Kader Tentang KB melalui media audio visual dan leaflet sehingga pada akhirnya masyarakat berperan aktif dalam memberikan informasi dan konseling tentang KB. Materi pada pelatihan tentang metode kontrasepsi antara lain pil kontraselsi, suntik, IUD, implant, MOW dan MOP.

\section{SASARAN}

Sasaran pada kegiatan ini adalah masayarakat dan kader kesehatan yang terdapat di Dusun Bopala Desa Menganti Kecamatan Kesugihan Cilacap 


\section{E. TEMPAT DAN WAKTU}

Posyandu Dusun Bopala Desa Menganti Kecamatan Kesugihan Kabupaten Cilacap. Waktu pelaksanaan kegiatan adalah bulan Juli tahun 2017.

\section{F. PELAKSANA}

Tim pelaksana kegiatan terdiri dari satu orang satu Ketua bergelar Magister Kebidanan. Gelar tersebut diperoleh dari Universitas Padjadjaran (UNPAD) Bandung, anggota satu bergelar Magister dan Universitas Muhammadiyah Yogyakarta (UMY), dan satu bergelar Magister Sains dari Universitas Gajah Mada (UGM). Pengabdian ini juga melibatkan 2 mahasiswa kebidanan. Tim pengusul adalah pengajar mata kuliah kebidanan dan keperawatan dan farmasi. Pengabdian ini juga melibatkan 2 mahasiswa kebidanan.

\section{G. HASIL KEGIATAN}

Pengabdian masyarakat ini menggunakan penilaian menggunakan kuesioner untuk memperoleh data primer dari responden meliputi pengetahuan dengan menggunakan kuesioner. Jumlah sampel yang didapatkan adalah 20 orang yang terdiri dari 15 orang ibu dan 5 orang bapak. Kegiatan penyuluhan dimulai dengan pembukaan, pre test pemateri melakukan penggalian tingkat pengetahuan kader tentang alat kontrasepsi, kemudian diberikan materi tentang alat kontrasepsi, diskusi tanya jawab dan diakhiri dengan post test.

Peningkatan partisipasi pria Dalam Program KB menjadi isu penting dewasa ini. Sesuai rekomendasi dari Konferensi Internasional Kependudukan dan Pembangunan (ICPD) tahun 1994 di kairo dan Convention on the Elimination of All Forms of Discrimination Againts Women (CEDAW), Indonesia telah mulai melaksanakan pembangunan yang berorientasi pada keadilan dan kesetaraan gender dalam Program KB dan KR. Sejak tahun 2004, pemerintah sepakat untuk meningkatkan partisipasi pria dalam Program KB dan KR menjadi delapan persen.
Berdasarkan hasil pengamatan dan diskusi selama kegiatan pelatihan saat penyampaian materi respon peserta terhadap materi yang disampaikan baik teknis maupun non teknis cukup baik, dan dari evaluasi sebelum penyampaian materi dan setelah penyampaian materi respon peserta cukup baik, hal ini ditandai dengan adanya peningkatan pemahaman peserta dalam menjawab sejumlah daftar pernyataan pre test dan post test yang diberikan. Terdapat peningkatan rerata pengetahuan dari rerata 56,1 menjadi 63,1.

Pelatihan dan pembentukan kader ini mendapat sambutan yang baik dari pemerintahan desa, kader dan tokoh masyarakat serta masyarakat. Di Dusun Bopala Desa Menganti akan didirikan Kampung KB sehingga pelatihan dan pembentukan kader peduli KB (KaPeKB) ini merupakan langkah awal menujua Kampung KB. Berdasarkan keterangan dari peserta pelatihan kegiatan seperti ini menambah informasi mereka tentang KB khususnya alat kontrasepsi sehingga kader yang telah terbentuk dapat memberikan wawasannya di masyarakat. Hal ini dilakukan evaluasi kemampuan kader $\mathrm{KB}$ dalam menyampaikan materi tentang $\mathrm{KB}$ di kegiatan Posyandu.

\section{Hasil}

\section{a. Karakteristik Peserta Pelatihan}

Karakteristik peserta pada kegiatan ini usia terbanyak usia 30-40 tahun tahun sebesar 12 orang $(60 \%)$ dan paling sedikit usia $>51$ tahun sebesar 1 orang (5\%). Jenis Kelamin terbanyak perempuan sebesar 15 orang $(75 \%)$, laki-laki 5 orang $(25 \%)$. Tingkat pendidikan terbanyak SD berjumlah 8 orang $(40 \%)$ dan SMP dan SMA masing - masing sebesar 6 orang $(30 \%)$. Pekerjaan terbanyak ibu rumah tangga sebesar 12 orang $(60 \%)$ dan paling sedikit dagang sebesar 1 orang $(5 \%)$. 


\section{b. Tingkat Pengetahuan Kader Tentang Alat Kontrasepsi}

Tabel 1

Tingkat pengetahuan kader KB (KaPeKB) pre dan post pelatihan di Desa Menganti Tahun 2017

\begin{tabular}{lcccc}
\hline Kategori & \multicolumn{2}{c}{ Pre test } & \multicolumn{2}{c}{ Post test } \\
\hline & $\mathrm{F}$ & $\%$ & $\mathrm{~F}$ & $\%$ \\
\hline Baik & 2 & 10 & 9 & 45 \\
Cukup & 18 & 90 & 11 & 55 \\
Kurang & 0 & 0 & 0 & 0 \\
\hline Jumlah & 24 & 100 & 24 & 100
\end{tabular}

Sumber : data primer tahun 2017

\section{c. Pembahasan}

Tingkat pengetahuan kader tentang alat kontrasepsi di Dusun Bopala Desa Menganti, menunjukkan adanya kenaikan nilai tingkat pengetahuan pada pre test nilai tertinggi 80 dan terjadi peningkatan di nilai post test dengan nilai tertinggi 87,5 . Tingkat pengetahuan post test terdapat peningkatan kategori Cukup menurun menjadi 55\% dan kategori Baik meningkat menjadi $45 \%$.

Tingkat pengetahuan kader yang ada di Dusun Bopala kemungkinan dipengaruhi oleh faktor lingkungan yang ada. Kader yang ada di lingkungan tersebut dikarenakan sedikit kegiatan penyuluhan tentang kesehatan sehingga hal tersebut menjadi pemicu dari sedikitnya kader untuk memperoleh informasi. Sehingga saat dilakukan pengabdian masyarakat tingkat pengetahuan diperoleh hadil dengan tingkat pengetahuan cukup.

Salah satu kemungkinan yang mempengaruhi adalah usia kader, Menurut Elisabet BH yang dikutip Nursalam (2003), usia adalah umur individu yang terhitung mulai saat dilahirkan sampai berulang tahun. Sedangkan menurut Huclok (1998), semakin cukup umur tingkat kematangan dan kekuatan seseorang akan lebih matang dalam berikir dan bekerja. Dari segi kepercayaan masyarakat seseorang yang lebih dewasa dipercaya dari orang yang belum tinggi kedewasaannya. Hal ini akan sebagai dari pengalaman dan kematangan jiwa

Meskipun sudah banyak media massa yang menayangkan tentang segala sesuatu yang terkait dengan alat kontrasepsi, tetapi kadang-kadang masyarakat masih membutuhkan penguatan dari orang-orang yang ada di sekitarnya untuk bisa merubah perilakunya. Hal ini sesuai dengan pernyataan Azwar yang menyatakan bahwa orang lain merupakan salah satu diantara komponen sosial yang ikut mempengaruhi sikap atau perilaku. Seseorang yang dianggap penting, seseorang yang diharapkan persetujuannya bagi setiap gerak tingkah dan pendapat, seseorang yang tidak ingin dikecewakan atau seseorang yang berarti khusus, akan banyak mempengaruhi pembentukan sikap terhadap sesuatu, dan kader merupakan salah satunya.

Melihat kondisi tersebut maka perlu adanya upaya untuk meningkatkan pengetahuan kader masyarakat khususnya pengetahuan tentang alat kontrasepsi.. Pemberdayaan kader sesuai dengan pendapat Syafe ${ }^{e c}$ (2010) bahwa kader merupakan penggerak masyarakat dalam program kemasyarakatan dan membantu dalam penyelesaian masalah yang dialami masyarakat. Pengetahuan yang lebih baik tentang manfaat serta akibat atau dampak yang ditimbulkan oleh suatu tindakan akan menyebabkan individu mengalami perubahan perilaku dengan berusaha mencari upaya pencegahan dan dampak (Notoadmodjo, 2012). Kader yang mengetahui dan memahami berbagai alat kontrasepsi akan memberikan informasi yang jelas. Hal ini menunjukkan bahwa pengetahuan kader akan memperbesar kemungkinan pasangan usia subur baik ibu dan suami akan menjadi akseptor KB terutama metode kontrasepsi jangka panjang (MKJP).

Pengetahuan kader yang baik tentang berbagai alat kontrasepsi kemungkinan disebabkan karena kader memperoleh informasi, oleh karena itu kader akan berusaha untuk menginformasikan hal tersebut kepada masyarakat. Hal tersebut 
sesuai dengan teori yang menyatakan bahwa faktor penting yang membentuk tindakan seseorang adalah pengetahuan yang diperoleh (Notoadmodjo, 2012). Kemungkinan hal lain yang dapat menyebabkan tingkat pengetahuan kader Posdaya desa Penggalang baik adalah kader sudah terpapar banyak tentang kesehatan dan kader mendapatkan informasi dari pihak Puskesmas dalam hal ini bidan desa pada saat dilakukan pertemuan rutin.

Hasil di atas menunjukkan adanya peningkatan yang bermakna terhadap pengetahuan yang diberikan pendidikan kesehatan dengan baik sesuai dengan teori Wood yang menyatakan bahwa pendidikan kesehatan dapat berpengaruh terhadap kebiasaan, sikap, dan pengetahuan yang berhubungan dengan kesehatan perorangan, masyarakat, dan bangsa. Pendidikan Kesehatan adalah semua kegiatan yang dilakukan untuk memberikan atau meningkatkan pengetahuan, sikap, dan praktik masyarakat dalam memelihara dan meningkatkan derajat kesehatan mereka sendiri (Notoadmodjo, 2012).

Kader merupakan salah satu sumber informasi bagi masyarakat yang memegang peranan penting dalam kebenaran informasi yang diterima oleh masyarakat sebagai modal dalam pembentukan perilakunya terutama di bidang kesehatan (Suliha et al, 2000). Untuk menunjang fungsinya tersebut, para kader biasanya pernah mendapatkan penyuluhan tentang masalah- masalah kesehatan yang lazim terjadi di masyarakat. Walaupun kader kesehatan bukanlah tenaga kesehatan, karena mereka tidak secara khusus mempelajari dan mendalami tentang kesehatan, tetapi mereka dipercaya oleh masyarakat sebagai orang yang lebih mengerti tentang kesehatan dan menjadi penghubung masyarakat dengan petugas kesehatan.

Berdasarkan penelitian Laraeni (2014) bahwa terdapat peningkatan pengetahuan kader sebelum dan setelah penyegaran $\mathrm{p}$ value 0,00 . Hal ini beratri ada pengaruh penyegaran kader terhadap tingkat pengetahuan kader Posyandu. Hasil penelitian ini sesuai dengan teori L.Green (1991), bahwa pengetahuan yang dimiliki seseorang merupakan salah satu faktor pencetus (predisposing) untuk mempermudah seseorang bersikap dan berperilaku khusus, sejalan dengan Notoatmodjo (2010), yang menyatakan bahwa apabila penerimaan perilaku baru atau adopsi perilaku yang didasari oleh pengetahuan akan bersifat lebih langgeng (long lasting), dan apabila perilaku tidak didasari dengan pengetahuan tidak akan berlangsung langgeng.

\section{H. DAFTAR PUSTAKA}

1. Mulyandari. 2016, Faktor- faktor yang berhubungan dengan kesediaan ibu bersalin untuk pemasangan IUD pada kala IV persalinan di Klinik Bersalin di Kecamatan Teluk Bintan Provinsi Kepulauan Riau tahun 2015. Tesis repository.usu.ac.id/bitstream/123456789/5 7602/5/Chapter\%20I.pdf

2. Deal Baby Ediyanti dan Indawati R. 2014. Faktor Pada Ibu Yang Berhubungan Dengan Kejadian Komplikasi Kebidanan. Fakultas Kesehatan Masyarakat UNAIR. Jurnal Biometrika dan Kependudukan . Vo. 3. No 1. Juli 2014:1-7

3. Indriati. 2011. Analisis Faktor Kebijakan dan Pengetahuan Tentang Pelayanan KB yang Berhubungan dengan Pemilihan Alat Kontrasepsi IUD pada Ibu Pasangan Usia Subur Akseptor KB di kecamatan Pedurungan Kota Semarang. Tesis http://eprints.undip.ac.id/32630/

4. Laraeni Y, Afni Wiratni, 2014, Pengaruh Penyegaran Kader Terhadap Pengetahuan Dan Ketrampilan Kader Posyandu Menggunakan Dacin Di Wilayah Kerja Puskesmas Dasan Cermen Kecamatan Sandubaya Kota Mataram, Media Bina Ilmiah, Volume 8, No. 4

5. Muryanta Andang. 2010. Menggapai target 5. MDG's dalam program KB. Nasional

6. Nursalam. 2003. Konsep \& Penerapan Metodologi Penelitian Ilmu Keperawatan: Pedoman Skripsi, Tesis, dan Instrumen 
Penelitian Keperawatan. Jakarta. Salemba Medika

7. Tumini, 2010. Pengaruh Pemberian Konseling Terhadap Pengetahuan Tentang KB Dan Kemantapan Dalam Pemilihan Alat Kontrasepsi Pada Calon Akseptor KB (Studi di Puskesmas Ngunut Kabupaten Tulungagung) $\quad 2010 \quad$ Tesis File://C:/Users/radith/Downloads/3829.p df
8. Zahrah, 2015, Partisipasi Pria Dalam Program Keluarga Berencana 9KB) Di Kecamatan Pakal Surabaya, Kebijakan dan Manajemen Publik ISSN 2303 - 341X Volume 3, Nomor 2, Mei - Agustus 2015 FISIP, Universitas Airlangga

\section{DOKUMENTASI}
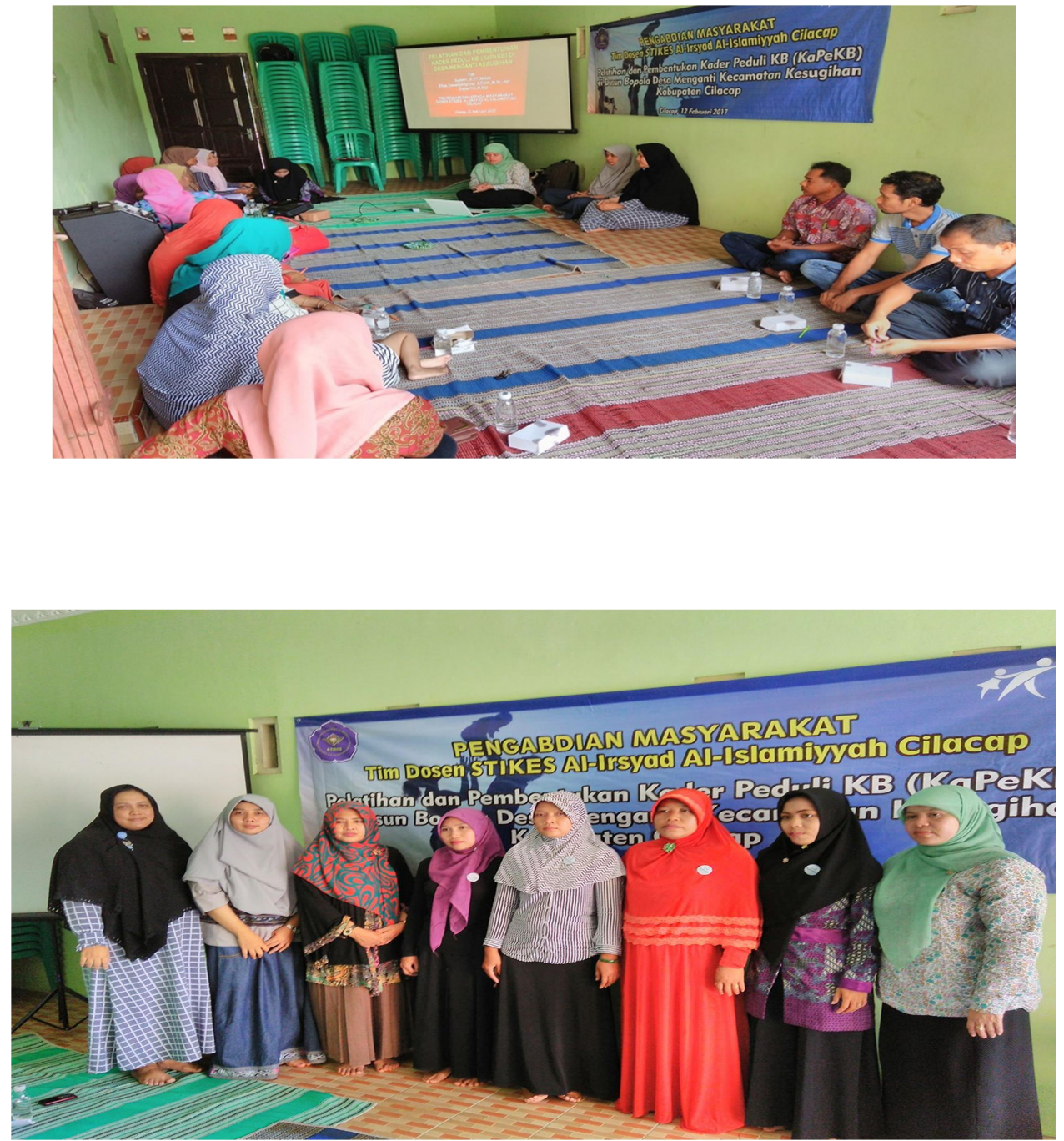